\title{
Relação pai-bebê no contexto da prematuridade: gestação, internação do bebê e terceiro mês após a alta hospitalar
}

\author{
Father-infant relationship in the context of preterm birth: \\ Pregnancy, hospitalization and third \\ month after discharge
}

\author{
Fernanda Borges de MEDEIROS ${ }^{1}$ \\ Cesar Augusto PICCININI'
}

\begin{abstract}
Resumo
O presente estudo buscou compreender o impacto do nascimento pré-termo na relação pai-bebê. Participaram do estudo três pais de bebês nascidos pré-termo, com idade entre 27 e 45 anos e que residiam com a mãe do bebê. Foi utilizado um delineamento longitudinal de estudo de caso coletivo, envolvendo entrevistas sobre a relação do pai com o bebê no período gestacional, no período de internação da criança e no terceiro mês após a alta hospitalar. Os relatos foram analisados por meio de análise de conteúdo qualitativa. De modo geral, constataram-se expressivas transformações na interação pai-bebê no lapso de tempo compreendido entre a gestação e o terceiro mês após a alta hospitalar. Além disso, os resultados revelaram a importância das visitas frequentes ao bebê durante a internação, para o estabelecimento daquela relação. Por outro lado, ficou evidente o receio de contato físico, em especial nas primeiras semanas de hospitalização, o que deve ser considerado nas intervenções pai-bebê durante a internação.
\end{abstract}

Palavras-chave: Nascimento prematuro. Relação pai-criança. Unidades de Terapia Intensiva.

\begin{abstract}
The aim of the study was to understand the impact of preterm birth on the father-infant relationship. Three fathers of preterm born children, aged 27-45 years, who live with the baby's mother, participated in the study. A collective-case study design was developed involving interviews about father-infant relationship in the context of preterm birth during pregnancy, hospitalization and the third month after discharge. The reports of the participants were examined through qualitative content analysis. There have been significant changes in father-infant interactions between pregnancy

\footnotetext{
$\checkmark \nabla \nabla$

1 Universidade Federal do Rio Grande do Sul, Instituto de Psicologia, Programa de Pós-Graduação em Psicologia. R. Ramiro Barcelos, 2600, sala 111, 90035-003, Porto Alegre, RS, Brasil. Correspondência para/Correspondence to: C.A. PICCININI. E-mail: <piccinini@portoweb.com.br>

Artigo baseado na dissertação de F.B. MEDEIROS, intitulada "Paternidade no contexto da prematuridade: da internação do bebê ao $3^{\circ}$ mês após a alta hospitalar". Universidade do Rio Grande do Sul, 2012.

Apoio: Conselho Nacional de Desenvolvimento Científico e Tecnológico (Protocolo no 485.059/2012-6).
} 
and third month after discharge. The results revealed the importance of frequent visits to the baby during hospitalization for the establishment of the father-infant relationship. Furthermore, it was noted that father-infant relationship was marked by fear of physical contact, particularly during the first weeks of hospitalization, which should be considered in parent-infant interventions during hospital stay.

Keywords: Premature birth; Father-Child relations; Intensive Care Units.

O nascimento pré-termo, isto é, com menos de 37 semanas de gestação, tem sido considerado um problema de saúde pública no Brasil e no mundo, em particular em países em desenvolvimento. Trata-se de um dos problemas de saúde perinatal mais prevalentes no mundo (Beck et al., 2010) e no Brasil (Barros et al., 2005; Silveira, Santos, A.J.D. Barros, Matijasevich, Barros, \& Victora, 2008). Está associado tanto à mortalidade neonatal (Bercini, 1994; Ramos, Martins-Costa, Valério, \& Müller, 2011) como a diversas complicações clínicas, podendo afetar o desenvolvimento cerebral, cognitivo e socioemocional da criança (Linhares, Chimello, Bordin, Carvalho, \& Martinez, 2005; Zomignani, Zambelli, \& Antonio, 2009) e, ainda, a relação do pai com ela (Brazelton \& Cramer, 1992; Fegran, Helseth, \& Fagermoen, 2008; M.H. Klaus, Kennell, \& Klaus, 2000).

Mesmo em situação de nascimento a termo, após o parto, as mães e os pais são confrontados com um bebê que sempre os decepciona em alguma medida, necessitando ajustar a imagem idealizada durante a gestação ao bebê real que nasce (Lebovici, 1987). Ressalta-se que, no presente artigo, o termo "pais" refere-se tão somente ao "pai", no plural - e não ao casal formado por pai e mãe.

Na verdade, no nascimento de um bebê, estariam presentes no psiquismo da mãe e do pai três diferentes bebês: a criança imaginária dos sonhos e fantasias, o bebê que foi sendo construído durante a gravidez, evidenciado pelas características e ritmos de cada bebê, e o recém-nascido que será conhecido no nascimento (Brazelton \& Cramer, 1992). No caso do nascimento pré-termo, devido à condição de imaturidade biológica, o bebê que nasce é frágil, sonolento, imprevisível e imaturo, sendo muito diferente daquele imaginado durante a gestação (Klaus et al., 2000). Portanto, esse ajuste poderá ser mais difícil para os pais e as mães de um bebê pré-termo, que podem ter dificuldade de perceber que ele se desenvolverá e crescerá (Klaus et al., 2000).

Diferentemente de um bebê a termo, por nascer pequeno e imaturo, o bebê pré-termo torna-se extremamente dependente de cuidados intensivos e da tecnologia neonatal para a manutenção da vida. A internação é uma situação ansiogênica para as mães e os pais, pelo encontro com um bebê minúsculo e enrugado, envolto em tubos e equipamentos médicos (Miles \& Holditch-Davis, 1997). Durante as visitas, de acordo com esses autores, as mães e os pais podem presenciar mudanças de cor no bebê, episódios de apneia ou problemas respiratórios, o que pode incrementar a ansiedade deles. Além disso, durante a internação de seu bebê na Unidade de Terapia Intensiva Neonatal (UTINeo), pode ocorrer a morte de outros bebês e, com isso, as mães e os pais têm que enfrentar a ideia da morte de seu próprio bebê (Pinto, Graham, Igert, \& Solis-Ponton, 2004). Nesse contexto de grande estresse, por vezes a morte do próprio filho pode ser desejada, como forma de encerrar o sofrimento do bebê e deles próprios (Lamy, Gomes, \& Carvalho, 1997; Pinto et al., 2004).

Outra particularidade do contexto da prematuridade é que os pais e as mães têm pouco controle sobre o que se passa com o filho, tendo poucas oportunidades de exercer os cuidados iniciais e, com frequência, sentem-se incapazes de exercer o papel parental (Miles \& Holditch-Davis, 1997). Para Lebovici (1987), em razão de médicos e enfermeiras serem os responsáveis pelo cuidado do bebê pré-termo, esses profissionais podem ser vistos como os únicos capazes de cuidar, tocar e nutrir o bebê, enquanto as mães e os pais podem sentir-se não autorizados a cuidar dele, sentindo-se perigosos e punidos pela separação.

Nesse contexto estressante, ocorrem os primeiros contatos do pai com o filho nascido pré- 
-termo. Durante as primeiras semanas, o bebê possivelmente estará na incubadora, o que pode gerar inúmeras ansiedades e temores, podendo interferir na relação que se inicia. Em um estudo qualitativo com cinco pais de bebês pré-termo, nascidos entre 24 e 30 semanas de gestação, M. Hollywood e Hollywood (2011) observaram que os pais temiam tocar o bebê devido ao risco de infecção. Alguns estudos também apontam que os pais temem a morte do bebê, malformações, possíveis sequelas e/ou que o bebê pare de respirar (Barros, Menandro, \& Trindade, 2006; Coutinho \& Morsch, 2006; Löhr, Gontard, \& Roth, 2000; Tronchin \& Tsunechiro, 2006).

Considerando tais aspectos, diversos autores descrevem que a prematuridade pode interferir na formação do vínculo dos pais e mães com o bebê (Brazelton \& Cramer, 1992; Klaus et al., 2000). Eles podem ter medo de vincular-se ao bebê e perdê-lo, em especial, nos casos de risco de morte (Brazelton \& Cramer, 1992) e durante a internação (Jackson, Ternestedt, \& Schollin, 2003; Lamy et al., 1997).

Apesar desses medos e angústias tão presentes no contexto da prematuridade, a literatura também tem destacado que os pais conseguem se envolver afetivamente com seu bebê (Coutinho \& Mosch, 2006; Fegran et al., 2008; Linberg, Axelsson, \& Öhrling, 2008). Mais ainda, parte desses estudos tem evidenciado a importância das interações com o bebê durante o período da internação para o estabelecimento do vínculo (Fegran et al., 2008; Lindberg et al., 2008; Tronchin \& Tsunechiro, 2006). No que se refere especificamente aos pais dos bebês pré-termo, Fegran et al. (2008) demonstraram que, após o nascimento, eles se envolviam imediatamente com seu filho, o que parecia relacionado às experiências de contato físico e incentivo de aproximação por parte das esposas e equipe de saúde. De forma semelhante, na investigação de Lindberg et al. (2008) com pais de bebê pré-termo, evidenciou-se que a oportunidade de conhecer o bebê durante a hospitalização favorecia o vínculo pai-bebê. Tais resultados ressaltam a importância das mudanças no ambiente neonatal, as quais, nas últimas décadas, passaram a permitir a entrada não só da mãe, mas também do pai, assim como o surgi- mento do Método Mãe-Canguru, que se constitui em uma prática preconizada pela World Health Organization ([WHO], 2003).

Como se vê, diversos autores têm buscado compreender não só as relações iniciais entre mãe e bebê, mas também entre pai e bebê no contexto da prematuridade, durante a internação. No entanto, não foram encontradas investigações nacionais sobre a relação pai-bebê durante o período compreendido entre a gestação e o terceiro mês após a alta hospitalar. Nesse sentido, o presente estudo buscou compreender o impacto do nascimento pré-termo para a relação pai-bebê, desde a gestação até o terceiro mês após a alta hospitalar. Com base na literatura (Coutinho \& Mosch, 2006; Fegran et al., 2008; Lindberg et al., 2008), a expectativa inicial era de que, apesar das dificuldades associadas ao nascimento pré-termo, os pais apresentassem envolvimento emocional, mostrando-se sensíveis às necessidades do seu bebê e capazes de estabelecer um vínculo, especialmente após a alta.

\section{Método}

\section{Participantes}

Participaram deste estudo três pais cujas filhas tinham nascido pré-termo em hospitais públicos de Porto Alegre (RS). Os participantes tinham idade entre 27 e 45 anos, nível socioeconômico médio ou médio alto e residiam com a mãe do bebê. Dois pais eram primíparos, e um deles era multíparo. Todos os bebês eram do gênero feminino e não apresentaram malformações ou complicações clínicas sérias durante a internação nem após a alta hospitalar. A Tabela 1 apresenta algumas características sociodemográficas dos pais, bem como as características clínicas e tempo de internação dos bebês na UTINeo.

Os participantes faziam parte de um projeto longitudinal que acompanhou mães e pais e seus bebês nascidos pré-termo, desde o nascimento até o terceiro mês após a alta, investigando as relações das mães e pais com o filho. Dentre os sete casais acompanhados pela primeira autora do presente 
Tabela 1

Características sociodemográficas dos pais, características clínicas e tempo de internação dos bebês

\begin{tabular}{|c|c|c|c|c|c|c|c|}
\hline Caso & Idade & Escolaridade & Ordem nascimento & Peso ${ }^{\mathbf{e}}$ & $\mathrm{IGO}^{f}$ & Tempo de internação & Idade no terceiro mês após alta $\left(\mathrm{IC}^{\mathbf{g}}\right)$ \\
\hline P1 & 27 & Superior Incompleto & $1^{\mathrm{a}}$ & MBP & 28 & 2 meses e 4 dias & 6 meses (3 meses) \\
\hline P2 & 45 & $2^{\circ}$ grau completo & $1^{\text {a }}$ & EBP & 27 & 2 meses e 5 dias & 5 meses e 6 dias ( 2 meses) \\
\hline P3 & 33 & Superior Incompleto & $3^{a}$ & $\mathrm{BP}$ & 33 & 28 dias & 4 meses e 11 dias (3 meses) \\
\hline
\end{tabular}

Nota: ${ }^{\mathrm{e} B P}$ (Baixo Peso): inferior a $2.500 \mathrm{~g}$; MBP (Muito Baixo Peso): inferior a $1.500 \mathrm{~g}$; EBP (Extremo Baixo Peso): inferior a $1.000 \mathrm{~g}$; ${ }^{\mathrm{f}} \mathrm{ddade}$ gestacional obstétrica em semanas; ${ }^{9} \mathrm{C}$ (Idade Corrigida): é utilizada para avaliar o desenvolvimento dos bebês nascidos pré-termo nos primeiros anos de vida e é obtida através do seguinte cálculo: IC: Idade Cronológica em semanas - (40 semanas de gestação - idade gestacional ao nascimento).

Fonte: Rugolo, 2005

artigo, apenas três pais foram selecionados para este estudo, por terem eles concluído todas as etapas de coleta de dados previstas naquela pesquisa (internação e terceiro mês após alta hospitalar). Dentre os pais que desistiram, dois deles, ambos com filhos do gênero masculino, referiram dificuldades em conciliar o horário de trabalho, as visitas ao filho e o agendamento das entrevistas; um deles era multíparo de um bebê nascido pré-termo com Muito Baixo Peso (MBP); e o outro, primíparo de um bebê também com MBP. Os demais não chegaram a justificar a desistência; eram primíparos e pais de bebês nascidos pré-termo com Extremo Baixo Peso (EBP), do gênero masculino.

Assim, no presente trabalho, optou-se por incluir apenas os três pais que foram entrevistados e acompanhados pela primeira autora do presente artigo, até o terceiro mês após a alta do bebê, por se entender que esses casos possibilitariam maior oportunidade de aprendizagem, por terem sido os mais acessíveis e com quem a autora esteve por mais tempo, critério sugerido por Stake (1994). Ao mesmo tempo, buscou-se priorizar a compreensão de cada caso em si, sem buscar a saturação das respostas, o que implicaria um número maior de participantes (Barker, Pistrang, \& Elliot, 1994).

\section{Instrumentos e Procedimentos}

Foi utilizado um delineamento de estudo de caso coletivo (Stake, 1994), de caráter longitudinal, com o objetivo de compreender o impacto do nascimento pré-termo na relação pai-bebê. Além de buscar a compreensão de cada caso, foram examinadas as semelhanças entre os casos estudados.
Os participantes eram contatados em Unidades de Tratamento Intensivo Neonatal de hospitais de referência do Sistema Único de Saúde (SUS) da cidade de Porto Alegre (RS). Durante a internação do bebê, após o convite inicialmente feito às mães, os pais também foram convidados a participar do projeto longitudinal, sendo contatados na UTINeo ou por telefone. Isso se deu em torno de 3 a 4 semanas após o nascimento do bebê, quando estes, de modo geral, apresentavam condições clínicas estáveis.

Com aqueles que concordaram em participar, foi agendado um primeiro encontro na UTINeo onde seus filhos estavam internados. Nesse encontro, após a assinatura do Termo de Consentimento Livre e Esclarecido (TCLE), foi realizada a Entrevista sobre a paternidade no contexto da prematuridade no pós-parto, indagando sobre os seguintes aspectos: a experiência na UTINeo; a relação pai-bebê; a experiência como pai do bebê pré-termo; a relação com equipe da UTI Neonatal; a percepção sobre a mãe do bebê; e a rede de apoio do pai. No final do encontro, foi agendada nova entrevista para a semana seguinte.

A segunda entrevista investigou a experiência da paternidade na gestação e no parto no contexto da prematuridade, buscando identificar os sentimentos e as percepções do pai frente à gestação, ao parto e aos primeiros contatos com o bebê.

No terceiro mês após a alta hospitalar do bebê, as famílias foram contatadas novamente a fim de agendar uma visita à residência, quando os pais responderam à entrevista sobre a paternidade no contexto da prematuridade na pós-alta. Foram investigadas: a experiência e rotina em casa; a 
relação pai-bebê no terceiro mês após a alta; a experiência como pai de bebê pré-termo; a percepção sobre a mãe do bebê; a rede de apoio do pai; os sentimentos e percepções em relação à alta. Todas as entrevistas eram semiestruturadas e foram gravadas em áudio e, posteriormente, transcritas para análise.

O projeto longitudinal, do qual este estudo faz parte, foi aprovado pelos Comitês de Ética em Pesquisa do Instituto de Psicologia da Universidade Federal do Rio Grande do Sul (Processo $n^{\circ}$ 22009015/2009), do Hospital Materno-Infantil Presidente Vargas (Processo n 07/09) e do Grupo Hospitalar Conceição (Processo nº 063/09). O TCLE foi assinado em duas cópias pelos participantes, que receberam uma delas.

Análise de conteúdo qualitativa (Laville \& Dione, 1999) foi utilizada para investigar a relação pai-bebê em diversos períodos da transição para a paternidade no contexto da prematuridade: gestação, internação do bebê e terceiro mês após a alta hospitalar. Após a transcrição das entrevistas, foi realizada uma leitura exaustiva de todo material, buscando identificar os relatos do pai sobre sua relação com o bebê nascido pré-termo, com base em três categorias derivadas da literatura e das próprias respostas. A primeira, denominada "Interações pai-bebê na gestação", refere-se ao conceito de "interações imaginárias" de Brazelton e Cramer (1992), que designam as interpretações subjetivas dos pais de sua relação com o bebê durante a gestação. A segunda, "Interações pai-bebê na internação", envolveu as interpretações do pai sobre a relação com seu bebê durante a internação na UTINeo. Por fim, na terceira categoria, "Interações pai-bebê no terceiro mês após a alta hospitalar", foram consideradas as descrições do pai sobre a relação com o bebê após a alta hospitalar.

\section{Resultados}

A seguir, apresenta-se cada uma das categorias examinadas longitudinalmente, ilustradas com alguns dos relatos paternos. Após, discutem-se os resultados à luz da literatura, destacando-se as particularidades e semelhanças entre os casos.

\section{Interações pai-bebê na gestação}

Todos os Participantes $(\mathrm{P})$ descreveram algum tipo de interação com a filha durante a gestação: "Ah, eu perguntava se ela tava bem, como é que ela tava, se ela queria sair, se ela tava crescendo" (P1); "Ah, passava a mão na barriga e dizia: Cadê o pepé do pai?" (P3). No entanto, dois participantes (P2, P3), que não haviam planejado a gravidez, relataram poucos momentos de interação: "Não deu tempo [de conversar]" (P2); "Ah, não era todas as noites, mas eu brincava com a barriga, conversava com ela" (P3).

Com relação às reações do bebê, de modo geral, os pais não conseguiram descrever aquelas do período intrauterino, com exceção de um participante. Esse pai, ao descrever as interações durante a gestação, destacou que as reações da filha poderiam indicar uma rejeição a ele: "Cada vez que eu chegava, encostava nela, podia tá se mexendo. Encostava na barriga, ela parava. ... Não sei, de repente, tava rejeitando o pai, porque o pai briga com a mãe, coisa assim" (P3).

Quanto aos sentimentos paternos, para um dos participantes, qualquer possibilidade de interação durante gestação propiciava muita satisfação, na medida em que buscava conhecer sua filha ainda tão pouco real: "Eu ficava ouvindo às vezes também na barriga pra escutar [riso] ... A gente escutava um monte de coisa, né [riso], se era ela ou se não era, eu não sei" (P1). Os demais pais, que estabeleceram pouca interação durante a gestação, não relataram seus sentimentos.

Dificuldades na interação com a filha, durante a gestação, foram associadas ao surgimento da pré-eclâmpsia e à própria redução no tempo da gravidez. Os pais destacaram que o menor tempo de gestação influenciou a comunicação ou a percepção dos movimentos fetais: "Na época que ia dá pra sentir mais, aí, acabou que ela já nasceu, né? [riso] Porque com oito, nove meses, ela tá maior, dá pra sentir mais ela chutando, se mexendo dentro da barriga" (P1); "[Eu conversei] poucas vezes, porque [a gestação] durou muito pouco" (P2). Um desses pais contou que a gravidez de risco impôs uma rotina de cuidados com a esposa, dificultando 
a disponibilidade de tempo para conversar com a filha durante a gravidez: "O pouco tempo que tinha, eu estava preocupado com ela [esposa], cuidando a pressão [arterial] e tal" (P2).

\section{Interações pai-bebê na internação}

Ao descrever o período de internação da filha, dois pais revelaram o desejo de estar sempre perto e/ou saber notícias: "Ah, eu quero tá sempre com ela, sempre ficar com ela, o tempo que dá, pelo menos" (P1); "A gente tem a necessidade de vir aqui" (P2); "A gente não deixa um dia sem saber notícias dela" (P1). Por outro lado, para um dos participantes, as visitas na UTINeo eram breves, principalmente durante a primeira semana de internação: "É, entrava, mas não ficava muito ali, porque eu sinto que eu atrapalho ali, né" (P3).

De modo geral, durante a interação, os pais buscaram conversar ou estabelecer algum contato físico: "Eu boto a mão [nela] e converso" (P1); "Abro um pouquinho [a incubadora], boto a mão no pezinho pra passar energia pra ela" (P2). Ao relatar sobre as interações durante esse período, dois pais destacaram as frequentes conversas com suas filhas: "Ah, eu converso, falo com ela bastante" (P1). "Aqui [UTINeo] eu conversei muito com ela" (P2). Um deles (P2) considerou que isso se devia às condições clínicas da esposa, que a impossibilitaram de visitar a filha durante seus primeiros cinco dias de vida.

No que se refere ao contato físico, alguns pais ressaltaram que o evitavam pelo temor de infecção: "Até o toque assim é uma coisa que a princípio a gente evita, né, quando eles são muito prematuros" (P2); "Evitava mexer... preocupado com ela, vai que a gente mexa ali e traga alguma bactéria, algum vírus pra ela" (P3). Posteriormente, ao perceber o crescimento e aumento da imunidade da filha, um dos pais começou a estabelecer algum contato físico: "Agora que ela pegou mais pesinho [1.820 g], já tá com imunidade maior, eu até abro [incubadora] e mexo com ela ali, fico fazendo carinho na mão dela" (P3). Já outro participante descreveu que ofereceria colo quando ela crescesse: “Vou deixar pra pegá ela [1.475 g] quando ela tiver bem grande" (P2). Em contrapartida, um dos participantes buscava constantemente estabelecer contato físico durante as visitas na UTINeo: "Tô sempre passando a mão nela [1.180 g], no peito, na cabeça, nos bracinhos, perninhas, tudo que dá" (P1).

Ainda sobre a interação com a filha, dois pais demonstraram sensibilidade e capacidade de identificar as sensações e necessidades de um bebê frágil, em tratamento na UTINeo: "[Os médicos] dizem pra deixar a mão em cima. Só pra largar a mão em cima. Daí eu deixo a mão em cima como se fosse um cobertorzinho" (P1); "Ah, [eu] chegava lá [na UTINeo], conversava com ela que a mamãe tava dodói [internada em outro andar do hospital]. Que a mamãe não podia vê ela ainda. Pra ela entender. Entender que a mamãe tava se recuperando" (P2). Em seus relatos, esses pais também destacaram a percepção de que a comunicação, o contato físico e o estabelecimento do vínculo poderiam promover o crescimento, o aumento de peso e o desenvolvimento da filha: "Acredito que é bom conversar também, né? ... Eu sempre falo isso pra ela: 'Vamos pra casa!?, 'Vamos pra casa!?'. E tá adiantando!, porque ela tá crescendo bastante" (P1); "Fico passando a mão. Eles [equipe de saúde] falam que é importante o contato, que isso ajuda até ela criar, ganhar peso" (P1); "A gente pode entrar, olhar, falar, conversar. ... Ah, eu acho que isso é muito bom, tanto pra gente como pro bebê" (P2).

Com relação às reações da filha durante as interações, de modo geral, os pais interpretaram que elas Ihes eram receptivas: "Às vezes, ela tá dormindo, sonolenta, eu chego, converso, ela dá uma abridinha no olho" (P2); "Às vezes, eu vou fazer cosquinha nela pra vê se ela ri. Às vezes, ela dá umas risadinhas" (P1). Inclusive, um desses pais interpretava que a filha não desejava se separar: "Parece que ela não quer que a gente vá embora" (P1). Diferentemente, outro participante descrevia que, ao tocar na filha, ela continuava dormindo: "Ela segue dormindo, se espreguiça" (P3).

O relato dos participantes revelou que alguns pais sentiam que, ao falar ou se aproximar da incubadora, as filhas conseguiam perceber que eles estavam por perto, inclusive podendo reconhecer sua voz: "Só o que eu senti foi que ela percebe 
quando a gente tá junto assim, né" (P1); "Eu sinto que ela já me reconhece, entendeu? Acho que pela voz. Porque desde o primeiro dia, que eu estive aqui [UTINeo], eu conversei com ela" (P2).

Com relação aos sentimentos, dois pais ( $\mathrm{P} 2$, P3) relataram medos quanto ao contato físico com a filha durante a internação: "A enfermeira disse pra mim pegar [no colo] ontem, eu disse 'não, enquanto eu não tiver com essa tosse bem curada, não vou pegar ela [1 mês e 20 dias] pra proteger ela" (P2); "Eu tenho um pouco de medo de mexer nela. Tenho medo de machucar ela [1.820 g] que é tão pequeninha" (P3). Destaca-se que, nos dois casos, por apresentarem boas condições clínicas nesse período da internação, os pais já poderiam oferecer colo se desejassem.

De forma bastante diversa, para outro pai, cuja filha nasceu com 28 semanas de gestação, as recomendações da equipe de saúde quanto ao contato físico - as quais normalmente estabelecem restrições durante as primeiras semanas de vida dos bebês nascidos muito pré-termo -, geraram um sentimento de frustração: "Eu tenho que abrir a incubadora e, por causa do oxigênio que baixa, logo tem que fechar. O que eu faço é ficar ali do lado dela. ... Em princípio, a relação tá bem, né, mas eles [equipe de saúde] falam que não pode botar a mão muito nela. A gente não pode nem pegar ela no colo, nada" (P1). Cabe ressaltar que, em razão de a filha ter nascido com muito poucas semanas de gestação e com MBP (<1.500 g), esse pai só pôde oferecer o primeiro colo quando ela estava com 27 dias de vida, momento bastante esperado por ele. Esse pai também demonstrou pesar e tristeza diante da situação de separação: "É ruim ter que ir embora, deixar ela ali [UTINeo]" (P1).

Por outro lado, todos os pais revelaram satisfação ao descrever as interações com a filha, em especial pelo contato físico e pelo reconhecimento ou percepção do bebê: "Agora [27 dias] vou poder pegar ela no colo pela primeira vez. O tempo que der, eu vou ficar! [sorri]" (P1); "Ah, eu, assim, a minha relação com a $V$. [filha], como é que eu vou te descrever, tá ótima! Porque eu chego, eu sinto que ela já me reconhece, entendeu?" (P2); "Foi um momento especial até, puder vê ela acordadinha, daí, mexi no bracinho dela, ela ficava olhando" (P3).
Contudo, um dos pais relatou dificuldades na interação durante a internação na UTINeo. De acordo com ele, uma das particularidades desse contexto era a dificuldade de escutar o choro do bebê, estabelecer contato visual e lidar com as restrições ao contato físico: "É difícil ela tá com os olhos abertos para ver a gente" (P1); "É difícil tu não querer fazer um carinho, né?" (P1). Os demais pais não referiram dificuldades ao relatar sobre o período da internação.

\section{Interações pai-bebê no terceiro mês após a alta hospitalar}

No terceiro mês após a alta hospitalar, em todos os casos, as descrições sobre as interações envolveram diversas atividades, entre as quais se destacaram a dança, o colo, os passeios, o brincar e as conversas com a filha: "Ah, final de semana, eu brinco bastante com ela" (P1); "Eu danço com ela" (P2); "Às vezes, pego ela pra conversar, pra brincar com ela" (P3). Todos os pais mostraram-se mais vinculados, satisfeitos e comunicativos com suas filhas: "A gente tá interagindo ali, conversando e ela rindo, essas coisinhas assim, né, então, tá mais próxima a relação" (P3). Os pais demonstraram empatia e respeito ao ritmo da filha: "Às vezes, quando eu chegava, ela tava dormindo. Não pegava ela pra não atrapalhar o sono dela" (P1).

Com relação às reações da filha, de modo geral, os pais descreveram que seus bebês eram felizes, atentos e receptivos durante as interações: "Agora dá pra vê que ela entende, porque ela olha, presta atenção" (P1); "Ela adora que eu dance com ela" (P2); "Se eu começo a brincar com ela 'Ah, tá no colo do papai', daí ela abre aquele sorriso. Não é sempre, mas aí ela abre aquele sorriso dela" (P3). Todos os pais interpretaram que as filhas buscavam interagir em diversos momentos: "Ela passa a mão assim no meu rosto quando eu boto ela no colo. Tipo... ela tá interagindo do jeito dela" (P1); "A gente começa a conversar, daí, ela dá um sorriso, começa a fazer gestos com as mãos. Parece que ela está entendendo, quer conversar, né" (P3). Outro aspecto destacado por todos os pais foi a capacidade da filha de reconhecê-los: "Acho que ela conhece 
o papai!" (P1). Importante ressaltar que, no terceiro mês após a alta hospitalar, todos os bebês estavam com 2 ou 3 meses de idade corrigida.

Com relação aos sentimentos dos pais, no terceiro mês após a alta, eles revelaram satisfação e entusiasmo pelas reações do bebê durante as interações, em especial o sorriso: "Tu tem que vê, eu converso com ela, ela ri bastante. Ela ri, ela é um amor" (P2). "Às vezes, eu brinco com ela, e ela abre aquele sorriso. Daí, é muito gratificante" (P3) "Eu sempre faço careta, ela sempre dá risada quando me vê" (P1). Também demonstraram felicidade por perceber as filhas bastante interativas e/ou capazes de reconhecê-los: "Agora eu chamo, ela olha assim. É bem legal" (P1); "Esse sorrisinho que ela dá, tentando conversar... não digo conversar, mas interagir já com gestos e olhares" (P3). "Ah, é muito bom, gratificante, saber que [ela] está [me] conhecendo" (P3).

Apesar da satisfação proporcionada pela interação com a filha, um dos pais relatou que evitava oferecer colo durante as primeiras semanas após a alta: "Aqui em casa também custei um tempo ainda pra começar a pegar ela" (P3). Esse pai destacou o medo de machucar a filha pelo fato de ela ter nascido prematura, diferentemente das outras filhas, nascidas a termo: "Eu não pegava ela que eu tinha medo, porque ela era muito pequeninha. Agora que eu tô pegando ela [4 meses e 11 dias; IC 3 meses] no colo" (P3).

Com relação às dificuldades na interação com a filha, o principal desafio citado por todos os pais foi a interpretação do choro: "Isso é o mais difícil: entender o que ela tá querendo" (P1); "Às vezes, a gente fica perdido. Ela tá chorando, às vezes tu não sabe [o que é]. Será que ela tá com fome? Será que ela tá com sede?" (P2); "É complicado. Às vezes, ela está chorando, ela chora diferente. 'Bá, será que está sentindo dor?' Essas coisas que eu queria entender" (P3). Um desses pais verbalizou o desejo de que a filha pudesse falar, o que facilitaria a comunicação entre eles.

\section{Discussão}

Os resultados revelam que o nascimento pré482 -termo influenciou a relação pai-bebê, desde a gestação. Alguns participantes descreveram dificuldades na interação com seus bebês, relacionando-as à pré-eclâmpsia e ao nascimento prematuro. De fato, o menor tempo de gestação e os cuidados com a esposa afetaram a comunicação pai-bebê e a percepção de movimentos fetais. Apesar dessas dificuldades, ainda durante a gestação, pelo menos um dos pais do presente estudo (P1) buscava interagir com a filha de diversas formas, fosse conversando, escutando ou percebendo a movimentação fetal. Diferentemente dos outros participantes, esse pai acompanhou todas as consultas do pré-natal e as ultrassonografias, o que parecia proporcionar uma confirmação da existência do bebê (Finnbogadottir, Crang Svalenius, \& Persson, 2003) e a construção de uma imagem mental do bebê (Piccinini, Levandowski, Gomes, Lindenmeyer, \& Lopes, 2009). Isso, somado a outros fatores, contribuiu para o estabelecimento do vínculo com a filha ainda durante a gestação. Em contrapartida, para os demais pais (P2; P3), outros fatores possivelmente dificultaram a relação com o bebê durante a gestação: as preocupações com a esposa (Piccinini et al., 2009), o fato de não desejar ser pai e os conflitos conjugais (Finnbogadottir et al., 2003).

Após o nascimento do bebê, todos os pais do presente estudo se depararam com a separação, o aparato tecnológico, a incubadora e as recomendações da equipe de saúde, que naturalmente limitam as possibilidades de cuidados e interações. Embora todos os pais estivessem frequentemente na UTINeo, foram constatadas algumas particularidades no que se refere à qualidade dessa interação. Dois pais (P2, P3) demonstraram maior receio de estabelecer contato físico, particularmente nas primeiras semanas de hospitalização, por temerem risco de infecção, resultado que já havia sido apontado em estudo anterior (M. Hollywood \& Hollywood, 2011). Além disso, esses pais também consideravam que as filhas estariam mais protegidas na incubadora do que no colo deles. Um deles (P3) também demonstrou temor de que sua presença na UTINeo pudesse gerar transtornos, vindo a "atrapalhar" o tratamento do bebê, tanto que suas visitas geralmente eram muito rápidas. Apesar de ter sido estimulado pela equipe de saúde a cuidar e interagir com a filha durante a internação, esse pai parecia 
sentir-se incapaz e não autorizado a oferecer cuidados para ela (Lebovici, 1987; Miles \& Holditch-Davis, 1997). Isso possivelmente decorria da situação, marcada pela rejeição à notícia da gestação e à chegada de um novo bebê. Por outro lado, alguns pais (P1, P3) mostraram-se sensíveis, muito disponíveis afetivamente e capazes de reconhecer as necessidades físicas e afetivas de seus bebês desde a internação na UTINeo, resultado também encontrado por outros autores (Coutinho \& Morsch, 2006).

Embora a UTINeo e a incubadora limitassem a interação, diferentemente dos outros pais, desde o nascimento da filha, para um deles (P1), qualquer possibilidade de contato físico foi descrita com intensa emoção, muito entusiasmo e felicidade, em especial quando relatou sobre como imaginava que seria o primeiro colo. Por outro lado, as restrições ao contato físico e a impossibilidade de cuidar diretamente da filha geravam um sentimento de frustração e pesar. Pode-se pensar que, além de outros fatores, o planejamento da gravidez tenha facilitado a preparação psicológica para a chegada de um bebê, mesmo antes da notícia da gestação, colaborando para a qualidade da interação pai-bebê durante a internação. Se, de um lado, seu envolvimento durante a gestação favoreceu o vínculo e o desejo de contato físico com a filha na UTINeo, por outro lado, gerou um intenso sofrimento ao enfrentar a separação nos primeiros meses de vida dela.

Apesar dessas particularidades, para todos os pais, após o nascimento do bebê, a oportunidade de estar com a filha na UTINeo sempre que desejassem, contribuía para as interações e para a comunicação. Ficou claro o quanto a presença constante dos pais na UTINeo - possibilitando perceber o crescimento e as condições clínicas da filha -, favorecia que eles se ajustassem ao bebê e se vinculassem a ele, corroborando estudos anteriores (Fegran et al., 2008; Lindberg et al., 2008; Tronchin \& Tsunechiro, 2006). É importante enfatizar que o incentivo de aproximação, pela equipe de saúde, durante as visitas na UTINeo também contribuiu para um maior envolvimento dos pais, corroborando os achados de Fegran et al. (2008) - inclusive para um dos pais (P3) do presente estudo, que apresen- tou maiores dificuldades para estabelecer vínculo com a filha.

Após a alta hospitalar, ficou evidente que a satisfação dos pais estava associada à reciprocidade e à responsividade do bebê percebidas por eles, apoiando resultados encontrados por outros estudos com bebês nascidos a termo (Anderson, 1996; Krob, Piccinini, \& Silva, 2009). O desenvolvimento de comportamentos sociais, em particular o sorriso do bebê, favorece trocas recíprocas, proporcionando grande atração e encorajamento dos pais para conectar-se com ele (Anderson, 1996).

Em todos os casos estudados, após a alta hospitalar, os pais apresentaram-se mais vinculados, comunicativos e satisfeitos com a interação com a filha. Entretanto, um dos pais (P3), cuja filha apresentou o menor tempo de internação e as melhores condições clínicas desde o nascimento, ainda evitou oferecer colo nas primeiras semanas após a alta, o que decorria do temor de machucá-la. Desde a gestação, esse pai demonstrou grandes dificuldades na interação com a filha, que pareciam refletir os sentimentos vividos naquele período, marcado pela rejeição à notícia da gestação e uma grande insatisfação pela chegada de outro bebê. Nesse sentido, ressalta-se que a relação pai-bebê parece ter sido influenciada não só pela situação de nascimento prematuro, mas principalmente por outras situações adversas, com destaque para o fato de ele referir que não desejava ter outros filhos.

Os resultados do presente estudo apoiaram em grande parte as expectativas iniciais de que os pais estariam envolvidos emocionalmente e vinculados aos bebês particularmente após a alta hospitalar. Ressalta-se que algumas características das famílias e do contexto hospitalar favoreceram o estabelecimento do vínculo pai-bebê pré-termo, indicando a necessidade de considerá-las em futuras investigações. Entre esses fatores, destacaram-se: o desejo da paternidade, o planejamento da gestação, a participação no pré-natal e nas ultrassonografias, as visitas frequentes ao bebê durante internação e o estímulo de aproximação por parte da equipe da UTINeo.

Ao apontar fatores que contribuem para a relação pai-bebê nesse contexto, o presente estudo 
oferece subsídios para intervenções que visem promover a saúde e a qualidade de vida de bebês pré-termo e suas famílias. Nesse sentido, pode-se ressaltar a relevância do Método Mãe-Canguru, política de cuidados materno-infantis recomendada pela WHO (2003), que enfatiza a importância de, durante a internação, envolver não só as mães, mas também os pais dos bebês nascidos com baixo peso, em consonância com os resultados destacados no presente estudo.

Por fim, é importante ressaltar algumas limitações da presente investigação. Se, de um lado, os estudos de caso permitiram compreender cada um deles, de outro, exige cautela ao se extrapolarem os achados para outros casos e contextos (Stake, 1994). Trata-se de casos escolhidos por conveniência, de pais que se dispuseram a participar do estudo, provavelmente por estarem mais envolvidos com seus bebês e esposas. Além disso, por uma situação, fora do controle da primeira autora, os casos investigados envolveram exclusivamente de pais de meninas, com bom nível escolar e socioeconômico. Portanto, sugere-se que outras pesquisas possam incluir pais de crianças pré-termo do gênero masculino e com outras características sociodemográficas.

\section{Referências}

Anderson, A. M. (1996). The father-infant relationship: Becoming connected. Journal of the Society Pediatric Nurses, 1(2), 83-92.

Barker, C., Pistrang, N., \& Elliot, R. (1994). Research methods in clinical and counselling psychology. London: Wiley.

Barros, S. M. M., Menandro, P. R. M., \& Trindade, Z. A. (2006). Vivências paternas em UTI neonatal. Psicologia Hospitalar, 4(2), 1-18.

Barros, F. C., Victora, C. G., Barros, A. J. D., Santos, I. S., Albernaz, E., Matijasevich, A., ... Vaughan, J. P. (2005). The challenge of reducing neonatal mortality in middle-income countries: Findings from three Brazilian birth cohorts in 1982, 1993, and 2004. The Lancet, 365(9462), 847-854.

Beck, S., Wojdyla, D., Say, L., Betran, A. P., Merialdi, M., Requejo, J. H., ... Look, P. F. V. (2010). The worldwide incidence of preterm birth: A systematic review of maternal mortality and morbidity. Bulletin of the World Health Organization, 88(1), 31-38.
Bercini, L. O. (1994). Mortalidade neonatal de residentes em localidade urbana da região sul do Brasil. Revista de Saúde Pública, 28(1), 38-45.

Brazelton, T. B., \& Cramer, B. G. (1992). As primeiras relações. São Paulo: Martins Fontes.

Coutinho, H. R. B. C., \& Morsch, D. S. (2006). A paternidade em cuidados intensivos neonatais. Revista da Sociedade Brasileira de Psicologia Hospitalar, 9(1), 55-69.

Fegran, L., Helseth, S., \& Fagermoen, M. S. (2008). A comparison of mothers' and fathers' experiences of the attachment process in a neonatal intensive care unit. Journal of Clinical Nursing, 17(6), 810-816.

Finnbogadottir, H., Crang Svalenius, E., \& Persson, E. K. (2003). Expectant first-time fathers' experiences of pregnancy. Midwifery, 19(2), 96-105.

Hollywood, M., \& Hollywood, E. (2011). The lived experiences of fathers of a premature baby on a neonatal intensive care unit. Journal of Neonatal Nursing, 17(1), 32-40.

Jackson, K., Ternestedt, B. M., \& Schollin, J. (2003). From alienation to familiarity: Experiences of mothers and fathers of preterm infants. Journal of Advanced Nursing, 43(2), 120-129.

Klaus, M. H., Kennell, J. H., \& Klaus, P. H. (2000). Vínculo: construindo as bases para um apego seguro e para a independência. Porto Alegre: Artes Médicas Sul.

Krob, A. D., Piccinini, C. A., \& Silva, M. R. (2009). A transição para a paternidade: da gestação ao segundo mês de vida do bebê. Psicologia USP, 20(2), 269-291.

Lamy, Z. C., Gomes, R., \& Carvalho, M. (1997). A percepção dos pais sobre a internação de seus filhos em unidade de terapia intensiva neonatal. Jornal de Pediatria, 73(5), 293-297.

Laville, C., \& Dione, J. (1999). A construção do saber: manual de metodologia da pesquisa em ciências humanas. Porto Alegre: Artmed.

Lebovici, S. (1987). O bebê, a mãe e o psicanalista. Porto Alegre: Artes Médicas.

Lindberg, B., Axelsson, K., \& Öhrling, K. (2008). Adjusting to being a father to an infant born prematurely: Experiences from Swedish fathers. Scandinavian Journal of Caring Sciences, 22(1), 79-85.

Linhares, M. B. M., Chimello, J. T., Bordin, M. B. M., Carvalho, A. E. V., \& Martinez, F. E. (2005). Desenvolvimento psicológico na fase escolar de crianças nascidas pré-termo em comparação com crianças nascidas a termo. Psicologia: Reflexão e Crítica, 18(1), 109-117.

Löhr, T., Gontard, A., \& Roth, B. (2000). Perception of premature birth by fathers and mothers. Archives of Women's Mental Health, 3(2), 41-46.

Miles, M. S., \& Holditch-Davis, D. (1997). Parenting the prematurely born child: Pathways of influence. Seminars in Perinatology, 21(3), 254-266. 
Piccinini, C. A., Levandowski, D. C., Gomes, A. G., Lindenmeyer, D., \& Lopes, R. S. (2009). Expectativas e sentimentos de pais em relação ao bebê durante a gestação. Estudos de Psicologia (Campinas), 26(3), 373-382. http://dx.doi.org/10.1590/S0103-166X20 09000300010

Pinto, E. B., Graham, S., Igert, B., \& Solis-Ponton, L. (2004). El bebé prematuro, las vicisitudes de la parentalidad. In L. Solis-Ponton (Ed.), La parentalidad: desafio para el tercer milenio (pp.133-143). México: El Manual Moderno.

Ramos, J. G. L., Martins-Costa, S. H., Valério, E. G., \& Müller, A. L. L. (2011). Nascimento pré-termo. In Rotinas em obstetrícia. Porto Alegre: Artmed.

Rugolo, L. M. S. S. (2005). Crescimento e desenvolvimento a longo prazo do prematuro extremo. Jornal de Pediatria, 81(Supl 1), S101-S110.

Silveira, M. F., Santos, I. S., Barros, A. J. D., Matijasevich, A., Barros, F. C., \& Victora, C. G. (2008). Aumento da prematuridade no Brasil: revisão de estudos de base populacional. Revista de Saúde Pública, 42(5), 957-964.

Stake, R.E. (1994). Case studies. In N. Denzin \& Y. Lincoln (Eds.), Handbook of qualitative research (pp.236-247). London: Sage.

Tronchin, D. M. R., \& Tsunechiro, M. A. (2006). Cuidar e o conviver com o filho prematuro: a experiência do pai. Revista Latino-Americana de Enfermagem, 14(1), 93-101.

World Health Organization. (2003). Kangaroo mother care: A practical guide. Geneva: Author.

Zomignani, A. P., Zambelli, H. J. L., \& Antonio, M. A. R. G. M. (2009). Desenvolvimento cerebral em recém-nascidos prematuros. Revista Paulista de Pediatria, 27(2), 198-203.

Recebido: maio 29, 2013

Versão final: janeiro 23, 2014

Aprovado: abril 23, 2014 
